\title{
Stator Slitting of 12-Slot 10-Pole Concentrated Winding Motors
}

\author{
Yuichi Yokoi, Member, IEEE and Tsuyoshi Higuchi, Member, IEEE
}

\begin{abstract}
This paper proposes a design method of stator cores to modify the component ratio of space harmonics in the magnetic field due to stator windings for 12-slot 10-pole concentrated winding motors. The method inserts slit-like magnetic flux barriers in stator wound teeth. In fractional-slot concentrated winding motors, the magnetic field due to stator windings includes dominant space harmonics with a specific space harmonic that produces drive torque. These space harmonics give rise to undesirable effects that increase iron loss in cores and eddy-current loss in magnets. For 12-slot 10-pole motors with single-layer windings, the proposed method increases the driving space harmonic and decreases dominant detrimental space harmonics. This modification of the space harmonics leads to torque enhancement and efficiency improvement. The efficacy of the proposed method is determined by deriving the winding factor, estimating magnetic flux distribution and motor performance through a finite element method analysis, and demonstrating the actual motor performance of a prototype.
\end{abstract}

Index Terms - stator slitting, fractional-slot concentrated windings, space harmonics, winding factor, permanent magnet motors.

\section{INTRODUCTION}

$\mathbf{F}$ RACTIONAL-slot concentrated winding (FSCW) configurations have attracted much attention as an alternative to integral-slot distributed winding configurations in permanent magnet (PM) synchronous machines [1]. In FSCW configurations, a small fractional number of slots can be selected per pole for a high winding factor [2]-[8]. The fractional number of slots per pole reduces the development of cogging torque. The small number of slots decreases the cost of manufacturing. The concentrated or non-overlapping windings inherently provide short and low-volume end turns for low copper loss and short axial length design. In addition, the concentrated windings achieve a high slot fill factor and a low cost automated manufacturing when they are coupled with segmented stator structures [9]-[11]. However, the magnetic field due to these stator windings includes dominant space harmonics with a specific space harmonic that produces drive torque. These space harmonics give rise to undesirable effects that increase iron loss in cores and eddy-current loss in magnets [12]-[16].

Many design methods of stator windings have been developed to modify the component ratio of space harmonics in the magnetic field due to the windings. Multilayer winding configurations whose number of layers is greater than two are investigated to reduce detrimental space harmonics [17]-[23]. In particular, a three-layer winding configuration completely eliminates the fundamental space harmonic for 12-slot 10 pole machines [18], [19], [21]-[23]. In [24]-[26], the same

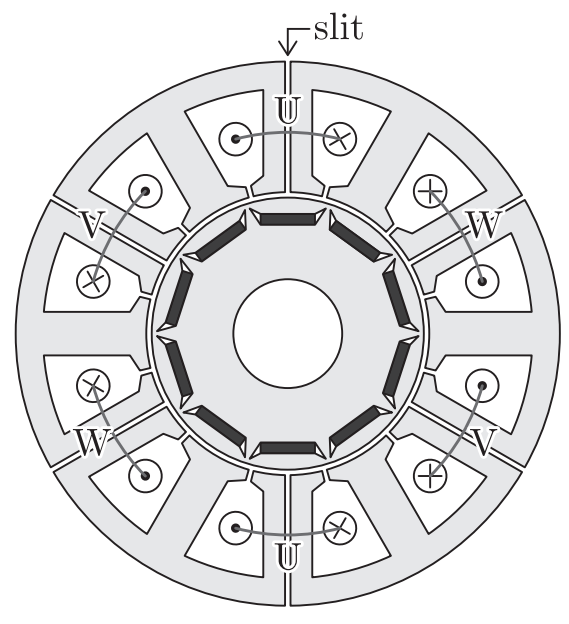

Fig. 1. Cross section of a 12-slot 10-pole PM motor that has a stator core with slits in wound teeth and single-layer windings (WT-SSM).

modification of space harmonics is achieved by a star-delta mixed connection in series [27]. The star-delta mixed connection in series is a connection of 3-phase winding terminals that is different from a conventional single-star or single-delta connection. The connection provides two groups of 3-phase windings that have a phase shift of $30^{\circ}$ electrical or 6-phase windings. However, these winding arrangements cannot reduce several space harmonics without a corresponding reduction of the driving space harmonic [21]. The winding factor of the space harmonics is the same as that of the driving space harmonic. The space harmonics are called slot harmonics because their order is determined by the number of slots and the number of poles [16], [21].

Several stator core structures have been proposed to improve the component ratio of space harmonics. In [28], [29], the widths of stator teeth are unequally adjusted to maximize the winding factor of all space harmonics for a 12-slot 10-pole machine with single-layer windings. This method determines the width of wound teeth at the pole pitch. In [30], magnetic flux barriers are precisely located in the stator yokes of 12slot 10-pole machines. For single-layer windings, this method reduces the fundamental space harmonic and slightly increases the driving or 5th and the 7th space harmonics. For doublelayer windings, the fundamental space harmonic is completely eliminated with the slight decrease in the 5th and 7th space harmonics. In [31], [32], magnetic flux barriers are inserted into the middle of alternate stator teeth without windings in 12slot machines. This stator design can reduce the fundamental and the 5th space harmonics and increase the 7th space 


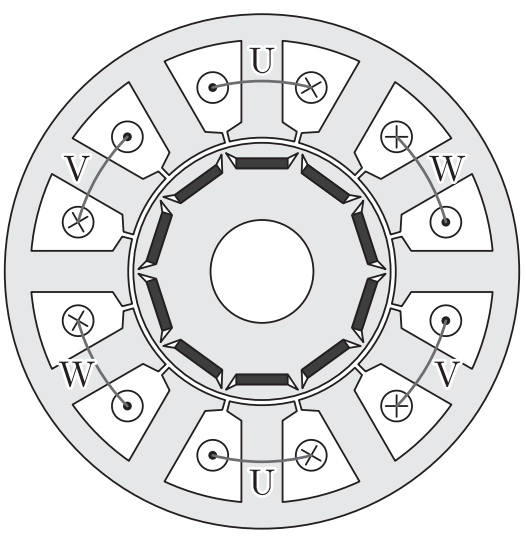

(a)

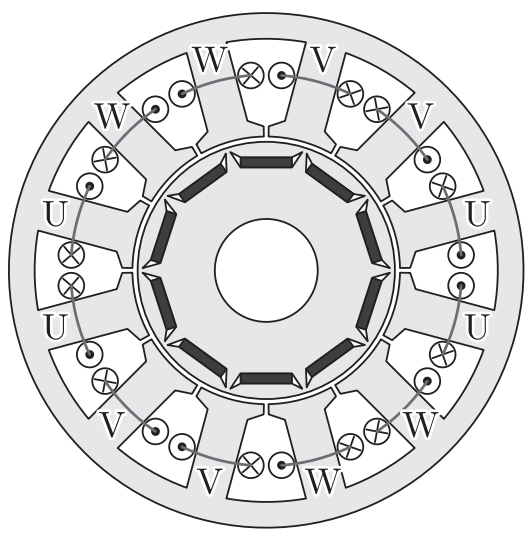

(b)

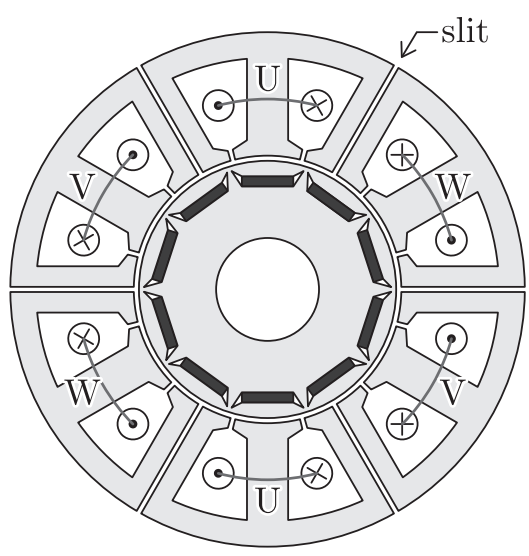

(c)

Fig. 2. Cross sections of 12-slot 10-pole PM motors that have (a) a conventional stator core with single-layer windings (SL-CSM), (b) a conventional stator core with double-layer windings (DL-CSM), and (c) a stator core with slits in unwound teeth and single-layer windings (UT-SSM).

harmonic. The modified component ratio of space harmonics is suitable for 12-slot 14-pole machines. In addition, the stator design achieves a so-called modular stator structure for simplified manufacturing and winding process. The similar modification of space harmonics can be obtained by inserting magnetic flux barriers into all stator teeth [31].

In this paper, a design method that inserts slit-like magnetic flux barriers in stator teeth, which is called stator slitting, is proposed to modify the component ratio of space harmonics in the magnetic field due to stator windings for 12-slot 10pole motors [33]. For 12-slot 10-pole motors with singlelayer windings, this method increases the 5th or driving space harmonic and decreases dominant detrimental space harmonics, namely, the fundamental and the 7th space harmonics. This modification of the space harmonics leads to torque enhancement and efficiency improvement. The efficacy of the proposed method is determined by deriving the winding factor, estimating magnetic flux distribution and motor performance through a finite element method (FEM) analysis, and demonstrating the actual motor performance of a prototype.

\section{Stator Slitting}

A stator slitting method is described and applied to a 12-slot 10-pole PM motor with single-layer windings. Fig. 1 shows the cross section of a motor whose stator core has slits in wound teeth, which is designated as WT-SSM.

\section{A. Concept of Stator Slitting}

The purpose of stator slitting is to modify the component ratio of space harmonics in the distribution of the air-gap flux density due to stator windings [31]. The space harmonic that should be increased is a specific space harmonic that produces the drive torque. The space harmonics that should be decreased are other dominant space harmonics that do not produce the drive torque but rather generate losses. In the stator slitting, slit-like flux barriers are located in teeth and their bottom yoke parts to separate the stator core. If the slits are located in yoke parts that adjoin slots, magnetic flux through the yoke parts is developed little. This location eliminates the magnetic effect of winding current in the slots that adjoin the slits. Slits reduce the development of space harmonics whose wavelength is longer than twice the slit pitch. For this reason, the slit pitch is determined to be longer than the pole pitch not to reduce the development of the driving space harmonic. The magnetic flux corresponding to the reduced space harmonics changes to flux corresponding to other space harmonics whose wavelength is shorter than twice the slit pitch in cores with a nonlinear magnetic property. The arrangement of slits is closely associated with the arrangement of stator windings because slits construct magnetic circuits for the flux induced by the stator winding current. Therefore, the slit arrangement is determined with the stator winding arrangement.

\section{B. Conventional Stator Winding Arrangements}

For 12-slot 10-pole machines, two arrangements of stator windings are generally employed: single-layer and doublelayer FSCWs. Fig. 2(a) shows a motor that has a conventional stator core with single-layer windings, which is designated as SL-CSM. Fig. 2(b) shows a double-layer conventional stator motor, which is designated as DL-CSM. The magnetic field due to the stator windings includes the 5th space harmonic as the driving harmonic that should be increased and the fundamental and the 7th space harmonics as other dominant space harmonics that should be reduced. The two winding arrangements exhibit different features [6] and generate slightly different distributions of the air-gap flux density.

\section{Arrangements of Slits and Windings}

In the stator design of a 12-slot 10-pole machine, slits and winding coils are symmetrically arranged not to induce additional space harmonics. Under the condition that the slit pitch is longer than the pole pitch, the slit pitch is determined at $60^{\circ}$ mechanical or slits are arranged in alternate teeth. To achieve a symmetrical design, slits are located at the center of the teeth and winding coils are arranged with single-layer windings. Based on SL-CSM, two arrangements of slits are 


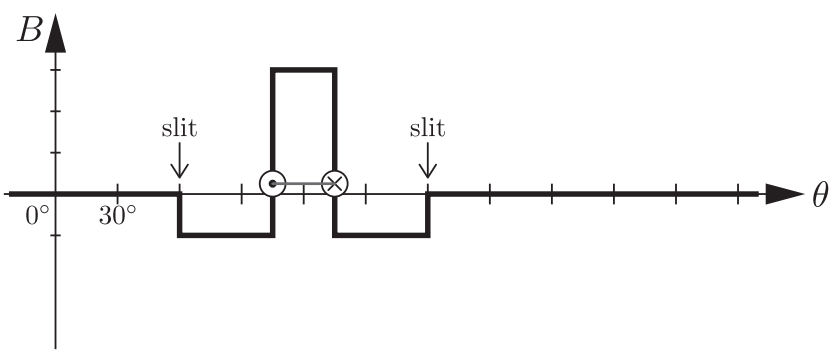

(a)

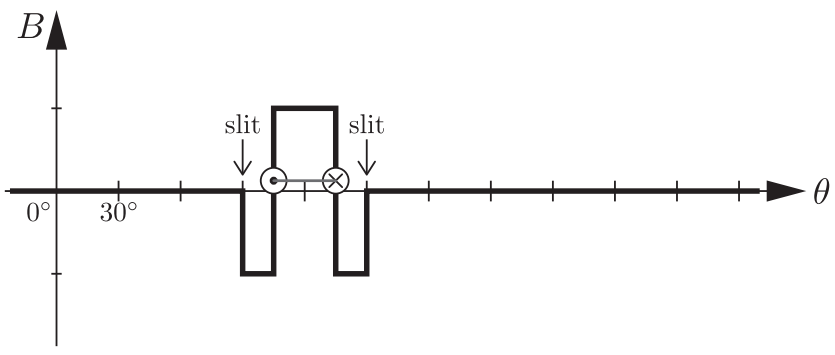

(b)

Fig. 3. Air-gap flux density distribution due to a winding coil for stator designs with (a) slits in wound teeth and (b) slits in unwound teeth.

provided by the stator slitting. One is a stator design of WTSSM in which slits are located in the wound teeth, as shown in Fig. 1. The other is a stator design in which slits are located in the unwound teeth, as shown in Fig. 2(c). The stator structure is magnetically identical to the stator structure in [31], [32]. The motor is designated as UT-SSM.

\section{Equivalent Winding Factor}

The effect of the stator slitting is theoretically estimated on space harmonics in the air-gap flux density distribution. The winding factor shows space harmonics in the air-gap flux density distribution due to stator windings. In general, the winding factor is defined for a stator core with a uniform permeance distribution. Thus, the winding factor does not represent the effect of the stator slitting. For this purpose, a winding factor is introduced for a stator core with a nonuniform permeance distribution due to slit-like flux barriers. In this paper, the calculated factor is called equivalent winding factor.

The equivalent winding factor is derived in reference to [33]. The slits are assumed to perform ideal flux barriers to allow no flux to pass. The equivalent winding factor $k_{\mathrm{w} \nu}$ is obtained from the distribution factor $k_{\mathrm{d} \nu}$ and the pitch factor $k_{\mathrm{p} \nu}$ :

$$
k_{\mathrm{w} \nu}=k_{\mathrm{d} \nu} \cdot k_{\mathrm{p} \nu},
$$

where $\nu$ is the order of space harmonics.

The distribution factor depends on the number of winding layers. The stator designs with single-layer windings, namely, SL-CSM, WT-SSM, UT-SSM, have an identical distribution of winding coils or an identical distribution factor. From [8], the distribution factor is given as

$$
k_{\mathrm{d} \nu}= \begin{cases}1, & \text { if } \nu \text { is odd } \\ 0, & \text { if } \nu \text { is even }\end{cases}
$$

TABLE I

Equivalent Winding FACTOR FOR THE STATOR DESIGNS

\begin{tabular}{crrrr}
\hline Order & SL-CSM & DL-CSM & WT-SSM & UT-SSM \\
\hline 1 & 0.2588 & 0.0670 & 0.0423 & 0.0088 \\
5 & 0.9659 & 0.9330 & 1.1824 & 0.7159 \\
7 & 0.9659 & 0.9330 & 0.7494 & 1.2159 \\
11 & 0.2588 & 0.0670 & 0.4753 & 0.5088 \\
13 & -0.2588 & 0.0670 & -0.4753 & -0.5088 \\
17 & -0.9659 & 0.9330 & -0.7494 & -1.2159 \\
19 & -0.9659 & 0.9330 & -1.1824 & -0.7159 \\
23 & -0.2588 & 0.0670 & -0.0423 & -0.0088 \\
\hline
\end{tabular}

For the double-layer windings such as DL-CSM, the distribution factor is derived [8] as

$$
k_{\mathrm{d} \nu}= \begin{cases}\sin \left(15^{\circ} \nu\right), & \text { if } \nu \text { is odd } \\ 0, & \text { if } \nu \text { is even. }\end{cases}
$$

The pitch factor is determined for each slit arrangement. For the conventional stator designs without slits such as SL-CSM and DL-CSM, the pitch factor is derived [8] as

$$
k_{\mathrm{p} \nu}=\sin \left(15^{\circ} \nu\right)
$$

Under the assumption of the ideal flux barriers, a coil current generates the air-gap flux density distribution, as shown in Fig. 3(a), for WT-SSM. The equivalent pitch factor can be obtained as

$$
k_{\mathrm{p} \nu}=\sin \left(15^{\circ} \nu\right)-\frac{1}{4} \sin \left(60^{\circ} \nu\right) .
$$

For UT-SSM, the air-gap flux density distribution is generated by a coil current, as shown in Fig. 3(b). The equivalent pitch factor can be obtained as

$$
k_{\mathrm{p} \nu}=\sin \left(15^{\circ} \nu\right)-\frac{1}{2} \sin \left(30^{\circ} \nu\right)
$$

The equivalent winding factor for the four stator designs is presented in Table I. The winding factor whose order is even is zero because the corresponding distribution factor is zero. The factor whose order is a multiple of 3 can be neglected because of the 3-phase balanced stator windings. For single-layer windings, the stator designs with slits, namely, WT-SSM and UT-SSM, have lower winding factors for the fundamental space harmonic than the conventional design or SL-CSM. The stator slitting can reduce the development of the fundamental space harmonic. The stator slitting in wound teeth increases the 5th space harmonic and decreases the 7 th harmonic. Therefore, the stator design WT-SSM is suitable for 12-slot 10-pole motors. In contrast, the stator slitting in unwound teeth decreases the 5th space harmonic and increases the 7th harmonic. This implies that the stator design UT-SSM is suitable for 12-slot 14-pole motors, which is consistent with the results in [31], [32].

\section{FEM ANALYSIS}

An FEM analysis is performed to validate the stator slitting. In this section, magnetic flux distribution and performance are calculated for the 12-slot 10-pole PM motors with different 
TABLE II

Dimesions OF ANALYZED MOTORS

\begin{tabular}{lr}
\hline Stator core length & $50 \mathrm{~mm}$ \\
Stator outer diameter & $160 \mathrm{~mm}$ \\
Rotor outer diameter & $88 \mathrm{~mm}$ \\
Air gap length & $1 \mathrm{~mm}$ \\
Stator tooth width & $15.5 \mathrm{~mm}$ \\
Stator slit tooth width & $18.0 \mathrm{~mm}$ \\
Slit width & $2.5 \mathrm{~mm}$ \\
Number of coils & 80 \\
\hline
\end{tabular}

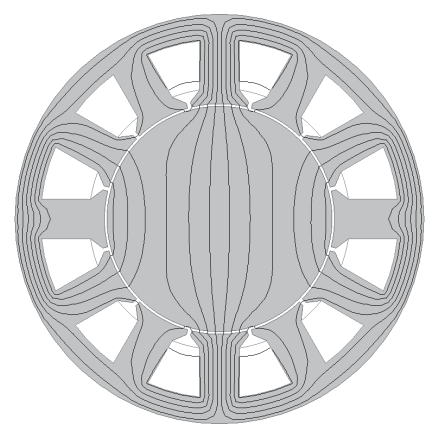

(a)

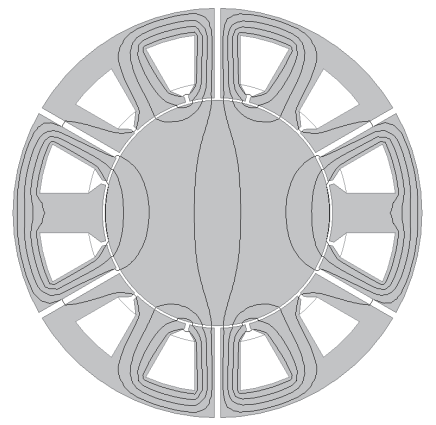

(c)

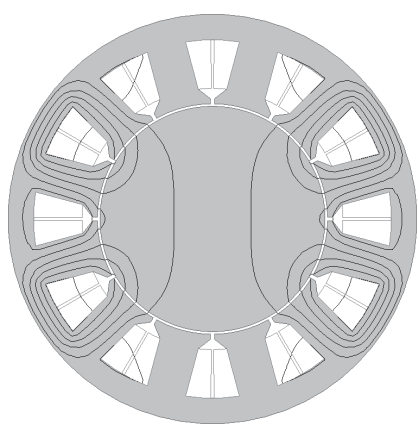

(b)

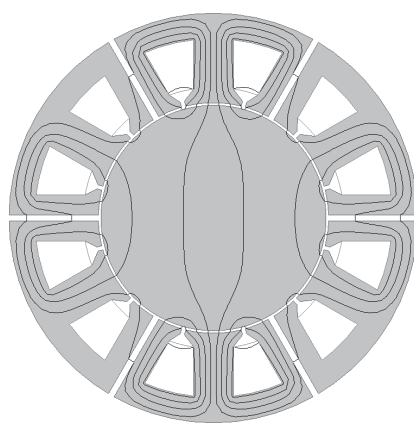

(d)
Fig. 4. Magnetic flux distribution in the motors without rotor magnets: (a) SLCSM, (b) DL-CSM, (c) WT-SSM, and (d) UT-SSM.

stator designs, namely, SL-CSM, DL-CSM, WT-SSM, and UTSSM. The dimensions of the analyzed motors are presented in Table II. The slit width is set at $2.5 \mathrm{~mm}$ to maximize the 5 th space harmonic for the dimensions. The width of slit teeth is increased by the slit width to uniform the core width of all the teeth. The materials of the cores and the magnets are modeled to exhibit nonlinear magnetic properties.

\section{A. Magnetic Flux Distribution}

For the motors without rotor magnets, the magnetic flux distribution due to stator windings is influenced by the stator slitting, as shown in Fig. 4. The flux distribution is calculated at the moment that a phase winding is supplied with a current of $10 \mathrm{~A}$ and the other two phase windings are supplied with a current of $-5 \mathrm{~A}$. In comparison with SL-CSM, the designs WT-SSM and UT-SSM exhibit more flux loops around only a slot. This corresponds to the increase of space harmonics whose wavelength is approximately equal to twice the slot

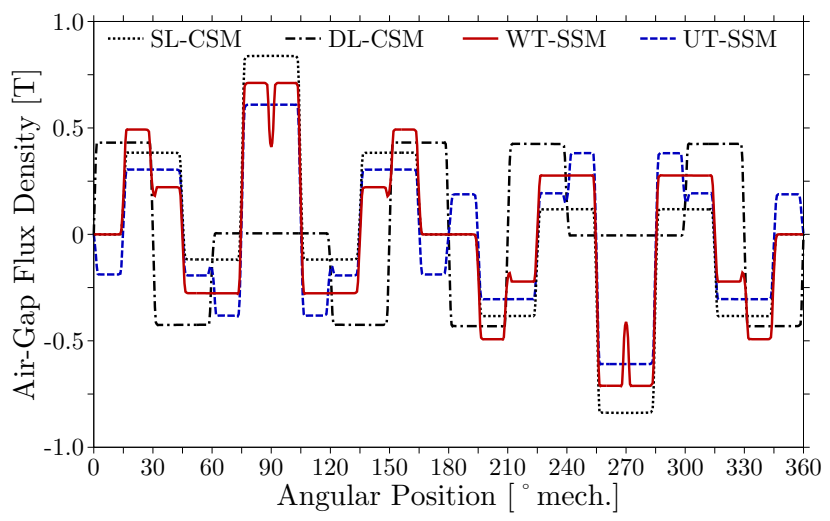

Fig. 5. Air-gap flux density distribution for the motors without rotor magnets.

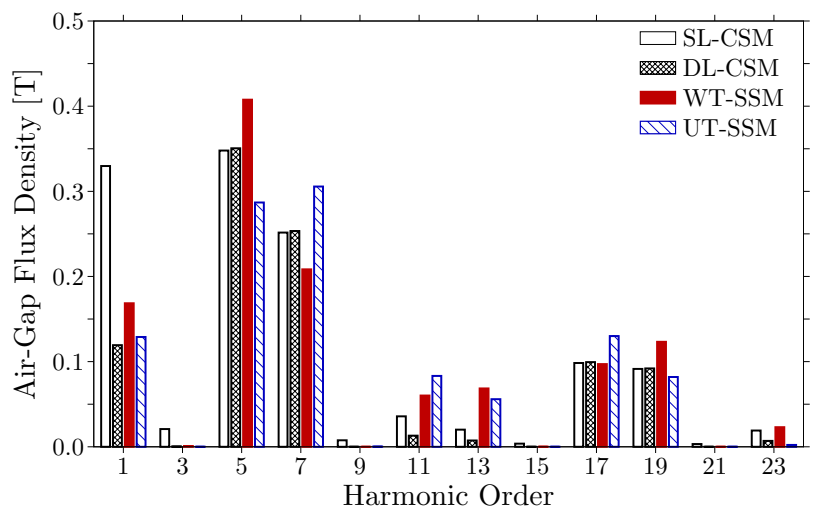

(a)

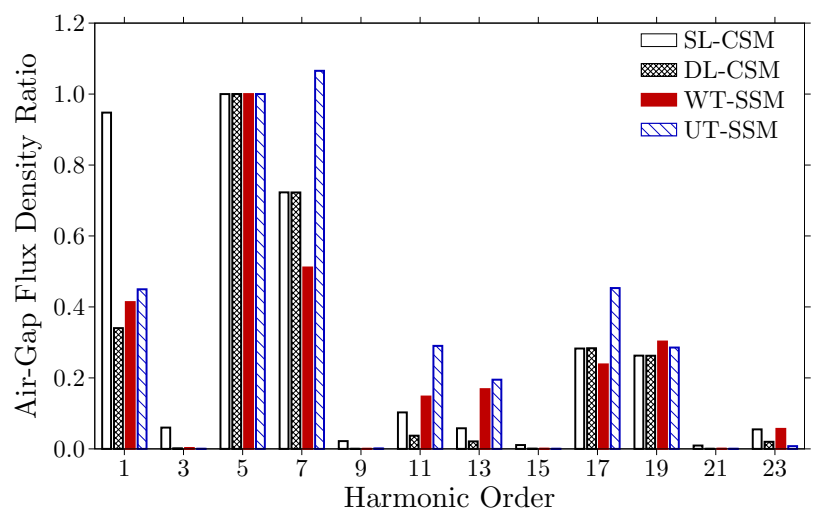

(b)

Fig. 6. Harmonic components in the air-gap flux density distribution for the motors without rotor magnets; (a) amplitude and (b) amplitude ratio.

pitch. Thus, the slits can increase the 5th and/or 7th space harmonics. The decreased number of flux loops that flow near the center of the rotor core corresponds to the decrease of the fundamental space harmonic.

The component ratio of space harmonics is modified by slitting wound teeth. The density distribution of the air-gap flux in Fig. 4 is calculated for the motors, as shown in Fig. 5. Harmonic components in the distribution are shown in Fig. 6(a). The comparison between SL-CSM and WT-SSM shows that the stator slitting in wound teeth increases the 5th 
space harmonic for the drive torque by approximately $17 \%$. Furthermore, this stator slitting decreases the fundamental harmonic by half and the 7th harmonic by approximately $17 \%$ as dominant harmonics that generate losses. However, the comparison between SL-CSM and UT-SSM shows that the stator slitting in unwound teeth decreases the 5th harmonic by approximately $18 \%$ and increases the 7 th harmonic by approximately $21 \%$. Therefore, this stator slitting is not suitable for 12-slot 10-pole machines although the fundamental harmonic decreases by more than $60 \%$. These stator slittings increase higher order space harmonics such as the 11th, 13th, 17th, and 19th ones. The increased space harmonics contribute to the enhancement of machine vibration and acoustic noise. However, these stator slittings decrease low order space harmonics of the radial force density distribution, which are the main cause of the machine vibration and the acoustic noise [34].

The modification of the harmonic component ratio by the stator slitting is qualitatively consistent with the theoretical estimation through the equivalent winding factor. The ratio of change in the 5th and the 7th harmonics is almost identical to the estimation. The slight difference is caused by the setting of the slit width. The slit width is set at $2.5 \mathrm{~mm}$ in the FE models and defined at $0 \mathrm{~mm}$ in the theoretical models for the equivalent winding factor. The reduction ratio of the fundamental cannot be estimated theoretically because of the difference in the permeability of slits. The slits are regarded as air in the FE models and ideal flux barriers that allow no flux to pass in the theoretical models.

The stator slitting changes the ratio of the 7th harmonic to the 5th harmonic. This is not achieved by only the winding arrangements [16], [21] such as DL-CSM. For an identical amplitude of the 5th space harmonic, the component ratio of space harmonics is shown in Fig. 6(b). In comparison with SL-CSM, the 7th space harmonic decreases for WT-SSM and increases for UT-SSM.

Based on the component ratio of space harmonics, the design WT-SSM has a potential to improve the performance of 12-slot 10-pole motors. However, the design UT-SSM is suitable for 12-slot 14-pole motors. In comparison with SLCSM, the design UT-SSM increases the 7th harmonic for the drive torque and decreases the fundamental and the 5th harmonics that cause losses in 12-slot 14-pole motors. With regard to the fundamental, these designs with slits have such reduction effects as the double-layer winding configuration or DL-CSM.

\section{B. Motor Performance}

No-load electromotive force (EMF) is improved by the stator slitting in wound teeth. Fig. 7(a) shows the waveforms of a no-load phase EMF for the motors at a rotational speed of $1,500 \mathrm{rpm}$. For the motors with single-layer windings, namely, SL-CSM, WT-SSM, and UT-SSM, the waveforms have in common that inflection points appear at rotational positions of approximately $4^{\circ}$ and $32^{\circ}$. However, these EMF waveforms exhibit different shapes near the top. In comparison with SL-CSM, the maximum value increases for WT-SSM and decreases for UT-SSM. The maximum value associates

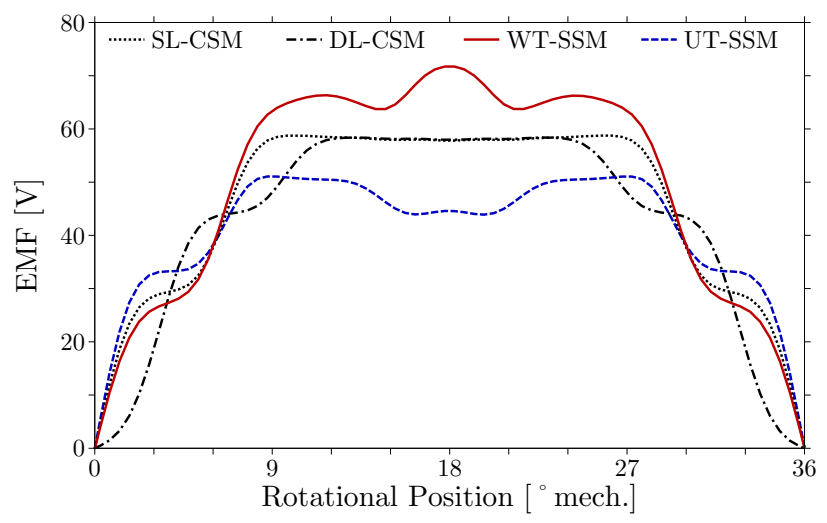

(a)

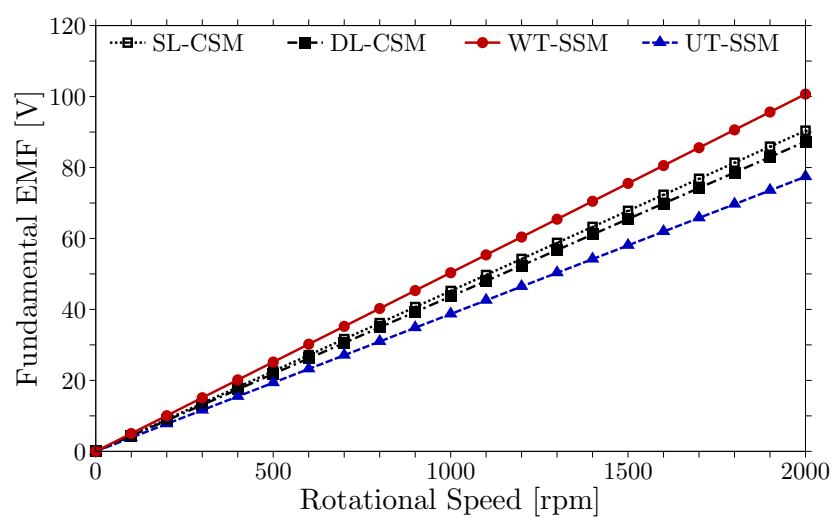

(b)

Fig. 7. No-load EMF for the motors; (a) waveform and (b) fundamental component as rotational speed.

with the magnitude of the fundamental component in the no-load EMF. The fundamental component of the no-load EMF corresponds to the EMF constant. Fig. 7(b) shows the fundamental component of the no-load EMF as rotational speed for the motors. The designs SL-CSM and DL-CSM exhibit almost identical characteristics as theoretically estimated by the 5th order winding factor. When compared with SLCSM, the design WT-SSM increases the fundamental EMF by approximately $11 \%$. The design UT-SSM decreases the fundamental by approximately $14 \%$. The increase ratio by the stator slitting in wound teeth is approximately half of the theoretical estimation because the slits in wound teeth decrease the surface area of the wound teeth on the air gap.

Torque production is enhanced by the stator slitting in wound teeth. Fig. 8(a) shows the waveforms of torque for the motors at a q-axis current of $10 \mathrm{~A}$ on the field oriented control. In comparison with SL-CSM, the design WT-SSM increases torque for all rotational position without aggravating torque pulsation. However, the design UT-SSM decreases torque. Fig. 8(b) shows the average torque as q-axis current for the motors. The designs SL-CSM and DL-CSM exhibit almost identical characteristics as theoretically estimated by the 5th order winding factor. When compared with SL-CSM, the design WT-SSM increases the average torque by approximately $10 \%$. The design UT-SSM decreases the average torque by approximately $14 \%$. Because of the same reason in 


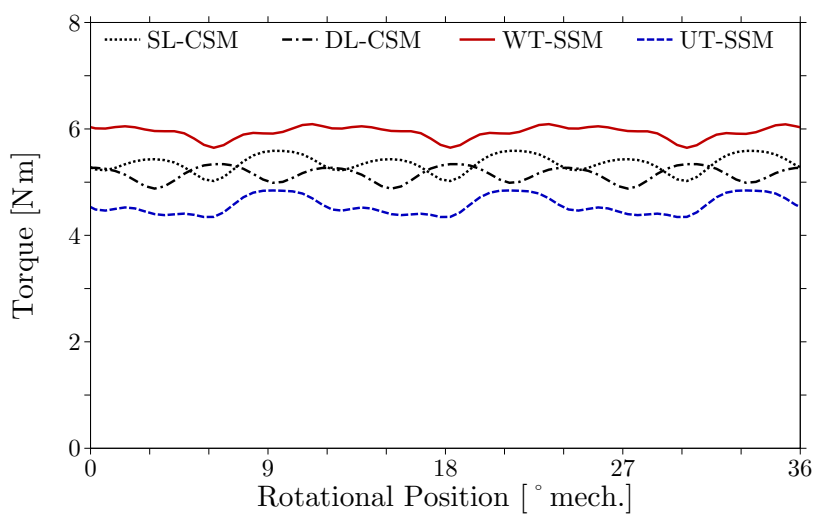

(a)

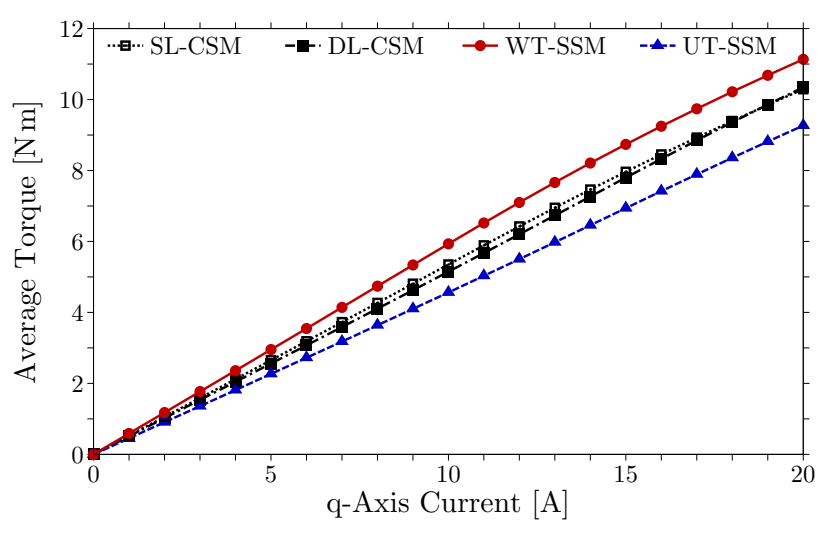

(b)

Fig. 8. Torque for the motors; (a) waveform and (b) average value as q-axis current.

TABLE III

PERFORMANCE AT AN OPERATION FOR THE MOTORS

\begin{tabular}{lrrrr}
\hline & SL-CSM & DL-CSM & WT-SSM & UT-SSM \\
\hline Current & $17.4 \mathrm{~A}$ & $17.6 \mathrm{~A}$ & $15.6 \mathrm{~A}$ & $19.8 \mathrm{~A}$ \\
Current phase & $21^{\circ}$ & $20^{\circ}$ & $22^{\circ}$ & $19^{\circ}$ \\
Rotational speed & $1,500 \mathrm{rpm}$ & $1,500 \mathrm{rpm}$ & $1,500 \mathrm{rpm}$ & $1,500 \mathrm{rpm}$ \\
Output torque & $10.0 \mathrm{~N} \mathrm{~m}$ & $10.0 \mathrm{~N} \mathrm{~m}$ & $10.0 \mathrm{~N} \mathrm{~m}$ & $10.0 \mathrm{~N} \mathrm{~m}$ \\
Output power & $1.57 \mathrm{~kW}$ & $1.57 \mathrm{~kW}$ & $1.57 \mathrm{~kW}$ & $1.57 \mathrm{~kW}$ \\
Loss in cores & $83.7 \mathrm{~W}$ & $64.5 \mathrm{~W}$ & $62.3 \mathrm{~W}$ & $80.4 \mathrm{~W}$ \\
Loss in magnets & $3.1 \mathrm{~W}$ & $1.2 \mathrm{~W}$ & $1.4 \mathrm{~W}$ & $2.7 \mathrm{~W}$ \\
Loss in windings & $90.8 \mathrm{~W}$ & $92.9 \mathrm{~W}$ & $73.0 \mathrm{~W}$ & $117.6 \mathrm{~W}$ \\
Efficiency & $89.8 \%$ & $90.8 \%$ & $92.0 \%$ & $88.6 \%$ \\
\hline
\end{tabular}

the fundamental EMF, the increase ratio by the stator slitting in wound teeth is approximately half of the theoretical estimation. The figure shows that the torque constant decreases for an average torque of more than $8 \mathrm{Nm}$. The decrease is caused by magnetic saturation in cores.

The efficiency is improved by the stator slitting in wound teeth. The performance at an operation with $10.0 \mathrm{Nm}$ and $1,500 \mathrm{rpm}$ for the motors is presented in Table III. Each motor produces a torque of $10 \mathrm{Nm}$ for a minimized current and a current phase of approximately $20^{\circ}$. The design WTSSM requires the lowest current to produce a torque of $10 \mathrm{~N} \mathrm{~m}$ among the stator designs. The stator slitting in wound teeth

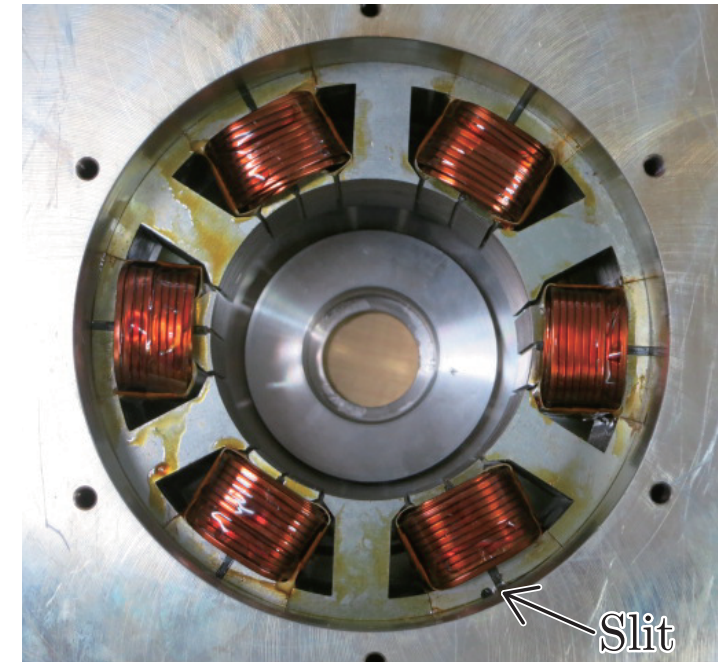

Fig. 9. The stator of the prototype.

decreases the required current by approximately $10 \%$. The design UT-SSM requires the highest current for the operation with $10 \mathrm{~N} \mathrm{~m}$. The stator slitting in unwound teeth increases the required current by approximately $14 \%$. The designs SL-CSM and DL-CSM require almost the same current for a torque of $10 \mathrm{Nm}$. The required current reflects the loss in windings. Hence, the design WT-SSM generates the lowest copper loss and UT-SSM generates the highest copper loss. The losses in cores and magnets are decreased by the stator slitting in wound teeth. When compared with SL-CSM, the design WTSSM decreases the loss in cores by approximately $26 \%$ and the loss in magnets by approximately $55 \%$. The design UTSSM decreases the loss in cores by approximately $4 \%$ and the loss in magnets by approximately $13 \%$. The decrease in the losses in cores and magnets is caused by the reduced fundamental and the 7th harmonic in the air-gap flux density distribution. In addition, with regard to the sum of the losses in cores and magnets, the design WT-SSM exhibits a lower value than DL-CSM. The decrease in the sum of the losses is mainly caused by the lower 7 th harmonic in the air-gap flux density distribution in spite of the slightly higher fundamental. Thus, the design WT-SSM achieves the highest efficiency. The efficiency $\eta_{\text {num }}$ is given by

$$
\eta_{\text {num }}=\frac{P_{\text {out }}}{P_{\text {out }}+P_{\text {loss }}},
$$

where $P_{\text {out }}$ denotes the output power and $P_{\text {loss }}$ represents the sum of losses in cores, magnets, and windings. The stator slitting in wound teeth improves the efficiency more than $2 \%$. The stator slitting in unwound teeth decreases the efficiency because of the increase in copper loss.

\section{EXPERIMENTAL VERIFICATION}

The method of stator slitting is verified experimentally. A prototype is constructed for the design WT-SSM. No-load EMF, torque, and efficiency are measured and compared with those obtained through the FEM analysis.

A prototype for the design WT-SSM is constructed, as shown in Fig. 9. The dimensions are presented in Table II. The 


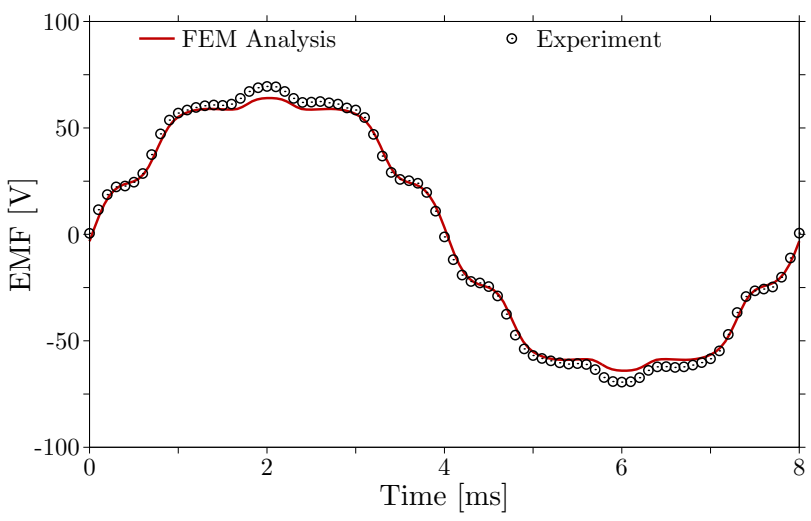

Fig. 10. No-load EMF induced by the prototype.

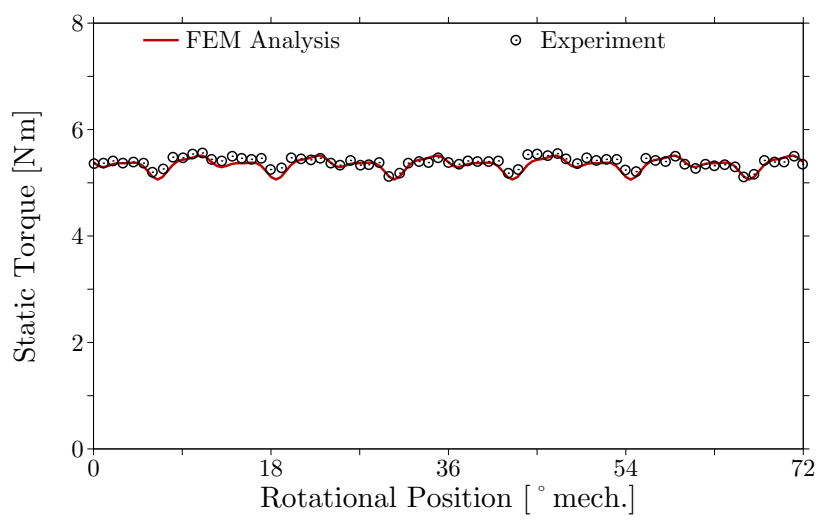

Fig. 11. Torque produced by the prototype.

gaps corresponding to slits are maintained by inserting plates that are made of a nonmagnetic material or Polyphenylene sulfide.

No-load EMF of the prototype is measured at a rotational speed of 1,500 rpm. Fig. 10 shows the waveform of the noload EMF. For comparison, the waveform calculated through the FEM analysis is shown in the figure. The calculated EMF coincides with the measured one.

Static torque of the prototype is measured at each rotor position at a q-axis current of $10 \mathrm{~A}$. Fig. 11 shows the measured torque with the torque calculated through the FEM analysis. The FEM analysis can accurately predict the actual torque production of the prototype.

Average torque of the prototype is measured as q-axis current at a rotational speed of $300 \mathrm{rpm}$, as shown in Fig. 12. For comparison, the average torque calculated through the FEM analysis is shown in the figure. In the FEM analysis, the indicated torque is obtained by subtracting a no-load torque from the corresponding electromagnetic torque because the FEM analysis cannot include the influence of the noload torque. The no-load torque is measured by rotating the prototype without input current at $300 \mathrm{rpm}$. The measured value of the no-load torque is $0.10 \mathrm{~N} \mathrm{~m}$. The electromagnetic torque corresponds to the torque calculated through the FEM analysis. The actual average torque can be predicted by the FEM analysis.

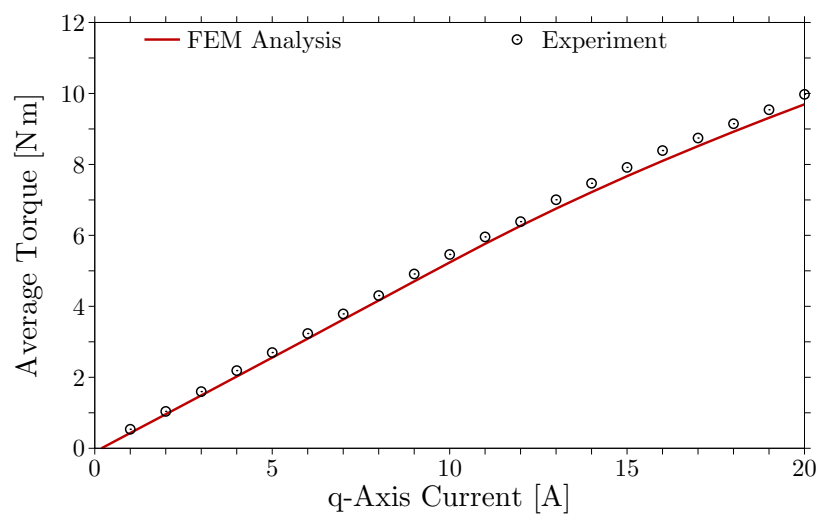

Fig. 12. Average torque as q-axis current in the prototype.

TABLE IV

PERFormance AT AN OPERATION FOR THE PROTOTYPE

\begin{tabular}{lrr}
\hline & FEM Analysis & Experiment \\
\hline Current & $11.5 \mathrm{~A}$ & $11.2 \mathrm{~A}$ \\
Current phase & $19^{\circ}$ & $18^{\circ}$ \\
Input Power & - & $1.11 \mathrm{~kW}$ \\
Rotational speed & $1,500 \mathrm{rpm}$ & $1,500 \mathrm{rpm}$ \\
Output torque & $6.38 \mathrm{~N} \mathrm{~m}$ & $6.39 \mathrm{~N} \mathrm{~m}$ \\
Output power & $1.00 \mathrm{~kW}$ & $1.00 \mathrm{~kW}$ \\
Loss in cores & $47.4 \mathrm{~W}$ & - \\
Loss in magnets & $0.7 \mathrm{~W}$ & - \\
Loss in windings & $39.0 \mathrm{~W}$ & - \\
Efficiency & $92.0 \%$ & $90.5 \%$ \\
\hline
\end{tabular}

The efficiency of the prototype is measured at an operation with $1.00 \mathrm{~kW}$ and $1,500 \mathrm{rpm}$. Table IV presents the performance at the operation for the prototype and its FEM model. For each motor, the input current is minimized on the field oriented control. In the experiment, the input power $P_{\text {in }}$ is directly measured with a power meter. The efficiency $\eta_{\exp }$ in the experiment is given by

$$
\eta_{\exp }=\frac{P_{\text {out }}}{P_{\text {in }}} .
$$

In the FEM analysis, the efficiency is given by (7). The output torque in the FEM analysis is obtained by subtracting the no-load torque, which is measured at $1,500 \mathrm{rpm}$, from the corresponding electromagnetic torque. The no-load torque is $0.18 \mathrm{Nm}$. The FEM analysis overestimates the efficiency of the prototype by $1.5 \%$. This is mainly caused by stray load losses that are not modeled in the FEM analysis. Therefore, the FEM analysis can predict the efficiency of the prototype with a sufficient degree of accuracy.

The method of stator slitting is verified through the comparison of the measured and calculated results for no-load EMF, torque, and efficiency. These results are consistent with each other. The FEM analysis and its results are validated to establish the efficacy of the stator slitting. The prototype demonstrates the feasibility of the stator slitting. 


\section{CONCLUSION}

A design method to insert slit-like magnetic flux barriers in stator teeth, which is called stator slitting, is proposed to modify the component ratio of space harmonics in the magnetic field due to stator windings. For a 12-slot 10-pole motor, the stator slitting in wound teeth increases the 5th or driving space harmonic and decreases dominant detrimental space harmonics, namely, the fundamental and the 7th space harmonics. This modification of the space harmonics achieves torque enhancement and efficiency improvement. The efficacy of the proposed method is determined theoretically, numerically, and experimentally. As a theoretical approach, the equivalent winding factor is introduced to represent the winding factor for a stator core with a non-uniform permeance distribution. This factor indicates that the stator slitting with ideal flux barriers in wound teeth can increase the driving space harmonic and decrease the two dominant detrimental space harmonics. An FEM analysis shows that an expected performance is achieved by a 12-slot 10-pole PM motor that has slits with a width of $2.5 \mathrm{~mm}$ in wound teeth. A prototype demonstrates no-load EMF, output torque, and efficiency predicted by the FEM analysis. In addition, the comparison of the stator designs clarifies that the stator slitting in wound teeth is suitable for 12-slot 10-pole machines and the stator slitting in unwound teeth is suitable for 12-slot 14-pole machines.

\section{ACKNOWLEDGMENT}

The authors would like to thank Shuhei Sakima for fruitful discussions on the design of the prototype and Ryuta Hashizume for assistance with the experiments. The permanent magnets of the prototype were provided by Hitachi Metals, Ltd.

\section{REFERENCES}

[1] A. M. EL-Refaie, "Fractional-slot concentrated windings synchronous permanent magnet machines: opportunities and challenges," IEEE Trans. Ind. Electr., vol. 57, no. 1, pp. 107-121, Jan. 2010.

[2] J. Cros and P. Viarouge, "Synthesis of high performance PM motors with concentrated windings," IEEE Trans. Energy Convers., vol. 17, no. 2, pp. 248-253, Jun. 2002.

[3] F. Magnussen and C. Sadarangani, "Winding factors and Joule losses of permanent magnet machines with concentrated windings," Proc. IEEE IEMDC, Madison, WI, USA, Jun. 2003, vol. 1, pp. 333-339.

[4] F. Libert and J. Soulard, "Investigation on pole-slot combinations for permanent-magnet machines with concentrated windings," Proc. ICEM, Cracow, Poland, Sep. 2004, pp. 530-535.

[5] N. Bianchi and M. D. Pré, "Use of the star of slots in designing fractional-slot single-layer synchronous motors," IEE Proc. -Electr. Power Appl., vol. 153, no. 3, pp. 459-466, May 2006.

[6] N. Bianchi, S. Bolognani, M. D. Pré, and G. Grezzani, "Design considerations for fractional-slot winding configurations of synchronous machines," IEEE Trans. Ind. Appl., vol. 42, no. 4, pp. 997-1006, Jul./Aug. 2006.

[7] A. M. EL-Refaie, M. R. Shah, R. Qu, and J. M. Kern, "Effect of number of phases on losses in conducting sleeves of surface PM machine rotors equipped with fractional-slot concentrated windings," IEEE Trans. Ind. Appl., vol. 44, no. 5, pp. 1522-1532, Sep./Oct. 2008.

[8] Y. Yokoi, T. Higuchi, and Y. Miyamoto, "General formulation of winding factor for fractional-slot concentrated winding design," IET Electr. Power Appl., vol. 10, no. 4, pp. 231-239, Apr. 2016.

[9] A. G. Jack, B. C. Mecrow, P. G. Dickinson, et al., "Permanent-magnet machines with powdered iron cores and prepressed windings," IEEE Trans. Ind. Appl., vol. 36, no. 4, pp. 1077-1084, Jul./Aug. 2000.
[10] H. Akita, Y. Nakahara, N. Miyake, and T. Oikawa, "New core structure and manufacturing method for high efficiency of permanent magnet motors," Conf. Rec. IEEE IAS Annu. Meeting, Salt Lake City, UT, USA, Oct. 2003, vol. 2, pp. 367-372.

[11] J. Shen, C. Wang, D. Miao, et al., "Analysis and optimization of a modular stator core with segmental teeth and solid back iron for PM electric machines," Proc. IEEE IEMDC, Niagara Falls, ON, Canada, May 2011, pp. 1270-1275.

[12] D. Ishak, Z. Q. Zhu, and D. Howe, "Eddy-current loss in the rotor magnets of permanent-magnet brushless machines having a fractional number of slots per pole," IEEE Trans. Magn., vol. 41, no. 9, pp. 24622469, Sep. 2005.

[13] N. Bianchi and E. Fornasiero, "Index of rotor losses in three-phase fractional-slot permanent magnet machines," IET Electr. Power Appl., vol. 3, no. 5, pp. 381-388, Sep. 2009.

[14] N. Bianchi, S. Bolognani, and E. Fornasiero, "An overview of rotor losses determination in three-phase fractional-slot PM machines," IEEE Trans. Ind. Appl., vol. 46, no. 6, pp. 2338-2345, Nov./Dec. 2010.

[15] J. Li, D. W. Choi, D. H. Son, and Y. H. Cho, "Effects of MMF harmonics on rotor eddy-current losses for inner-rotor fractional-slot axial flux permanent magnet synchronous machines," IEEE Trans. Magn., vol. 48, no. 2, pp. 839-842, Feb. 2012.

[16] E. Fornasiero, N. Bianchi, and S. Bolognani, "Slot harmonic impact on rotor losses in fractional-slot permanent-magnet machines," IEEE Trans. Ind. Electr., vol. 59, no. 6, pp. 2557-2564, Jun. 2012.

[17] H. Kometani, Y. Asao, and K. Adachi, "Dynamo-electric machine," U.S. Patent, 6,166,471, Dec. 26, 2000.

[18] K. Ito, K. Naka, M. Nakano, and M. Kobayashi, "Electric machine," U.S. Patent, 7,605,514 B2, Oct. 20, 2009.

[19] M. V. Cistelecan, F. J. T. E. Ferreira, and M. Popescu, "Three phase tooth-concentrated multiple-layer fractional windings with low space harmonic content," Proc IEEE ECCE, Atlanta, GA, USA, Sep. 2010, pp. 1399-1405.

[20] L. Alberti and N. Bianchi, "Theory and design of fractional-slot multilayer windings," IEEE Trans. Ind. Appl., vol. 49, no. 2, pp. 841-849, Mar./Apr. 2013.

[21] L. Alberti, M. Barcaro, and N. Bianchi, "Design of a low-torqueripple fractional-slot interior permanent-magnet motor," IEEE Trans. Ind. Appl., vol. 50, no. 3, pp. 1801-1808, May/Jun. 2014.

[22] A. Sun, J. Li, R. Qu, and D. Li, "Effect of multilayer windings on rotor losses of interior permanent magnet generator with fractional-slot concentrated windings," IEEE Trans. Magn., vol. 50, no. 11, 8105404, Nov. 2014.

[23] N. Bianchi, L. Alberti, M. Barcaro, "Design and tests of a fourlayer fractional-slot interior permanent-magnet motor,' IEEE Trans. Ind. Appl., vol. 52, no. 3, pp. 2234-2240, May/Jun. 2016.

[24] H. Vansompel, P. Sergeant, L. Dupré, and A. Van den Bossche, "A combined wye-delta connection to increase the performance of axialflux PM machines with concentrated windings," IEEE Trans. Energy Convers., vol. 27, no. 2, pp. 403-410, Jun. 2012.

[25] A. S. Abdel-Khalik, S. Ahmed, and A. M. Massoud, "Low space harmonics cancelation in double-layer fractional slot winding using dual multiphase winding," IEEE Trans. Magn., vol. 51, no. 5, 8104710, May 2015.

[26] A. S. Abdel-Khalik, S. Ahmed, and A. M. Massoud, "Effect of multilayer windings with different stator winding connections on interior PM machines for EV applications," IEEE Trans. Magn., vol. 52, no. 2, 8100807, Feb. 2016.

[27] J. Y. Chen and C. Z. Chen, "Investigation of a new AC electrical machine winding," IEE Proc. Electr. Power Appl., vol. 145, no. 2, pp. 125-132, Mar. 1998.

[28] D. Ishak, Z. Q. Zhu, and D. Howe, "Permanent-magnet brushless machines with unequal tooth widths and similar slot and pole numbers,' IEEE Trans. Ind. Appl., vol. 41, no. 2, pp. 584-590, Mar./Apr. 2005.

[29] S. P. Cheng and C. C. Hwang, "Design of high-performance spindle motors with single-layer concentrated windings and unequal tooth widths," IEEE Trans. Magn., vol. 43, no. 2, pp. 802-804, Feb. 2007.

[30] G. Dajaku, W. Xie, and D. Gerling, "Reduction of low space harmonics for the fractional slot concentrated windings using a novel stator design," IEEE Trans. Magn., vol. 50, no. 5, 8201012, May 2014.

[31] G. Dajaku and D. Gerling, "Low costs and high-efficiency electric machines," Proc. EDPC, Nuremberg, Germany, Oct. 2012.

[32] G. J. Li, Z. Q. Zhu, M. Foster, and D. Stone, "Comparative studies of modular and unequal tooth PM machines either with or without tooth tips," IEEE Trans. Magn., vol. 50, no. 7, 8101610, Jul. 2014.

[33] Y. Yokoi and T. Higuchi, "Design analysis of slit stator motors," Proc. ICEMS, Chiba, Japan, Nov. 2016. 
[34] J. Wang, Z. P. Xia, S. A. Long, and D. Howe, "Radial force density and vibration characteristics of modular permanent magnet brushless AC machine," IEE Proc. Electr. Power Appl., vol. 153, no. 6, pp. 793-801, Nov. 2006. 